\title{
Evaluation of a commercial test based on ligase chain reaction for direct detection of Mycobacterium tuberculosis in respiratory specimens
}

\author{
Avaliação do método comercial baseado na reação em cadeia da ligase para detecção direta \\ do Mycobacterium tuberculosis em espécimes pulmonares
}

\author{
Fabíola Karla Corrêa Ribeiro ${ }^{1}$, Valdério do Valle Dettoni ${ }^{1}$, Renata Lyrio Peres ${ }^{1}$, Solange Alves \\ Vinhas $^{1}$, Tatiana Resende Cón ${ }^{1}$, Reynaldo Dietze ${ }^{1}$ and Moisés Palaci ${ }^{1}$
}

\begin{abstract}
A ligase chain reaction DNA amplification method for direct detection of Mycobacterium tuberculosis (Abbott LCx MTB) in respiratory specimens was evaluated. Results from LCX MTB Assay were compared with those from acid fast bacilli smear, culture, and final clinical diagnosis for each patient. A total of 297 respiratory specimens ( sputum and bronchial lavage) from 193 patients were tested. The sensitivity, specificity, positive predictive value and negative predictive value of $L C x$ vs culture were $92.7 \%, 93 \%, 67.8 \%$ and $98.7 \%$, respectively. When compared to the clinical final diagnosis, the sensitivity, specificity, PPV and NPV for LCx were $88.9 \%, 96.8 \%, 86.5 \%$ and $97.4 \%$, respectively. The sensitivity of LCx MTB assay was 75\% for smear-negative, culture positive samples. The results indicate that LCX MTB assay is a rapid, simple and valuable technique as a complementary tool for the diagnosis of tuberculosis.
\end{abstract}

Key-words: Tuberculosis. Diagnosis. Molecular biology.

\section{RESUM0}

0 método de amplificação de DNA baseado na reação em cadeia da ligase (Abbott LCx MTB) foi avaliado para detecção do Mycobacterium tuberculosis em espécimes pulmonares. Os resultados do LCx MTB foram comparados aos resultados de baciloscopia, cultura e diagnóstico clínico para cada paciente. Um total de 297 espécimes (escarro e lavado broncoalveolar) de 189 pacientes foram testadas. Os valores de sensibilidade, especificidade, valor preditivo positivo e valor preditivo negativo do LCX vs cultura foram $92,7 \%, 93 \%, 67,8 \%$ e 98,7\%, respectivamente. Quando comparados ao diagnóstico clínico, os valores de sensibilidade, especificidade, VPP e VPN para o LCx foram 88,9\%, 96,8\%, 86,5\% e 97,4\%, respectivamente. A sensibilidade do LCx MTB foi de 75\% para as amostras com baciloscopia negativa e cultura positiva. Os resultados indicam que o teste LCx MTB é simples, rápido, eficiente e pode ser utilizado como um recurso complementar para o diagnóstico da tuberculose.

Palavras-chaves: Tuberculose. Diagnóstico. Biologia molecular.

The reemergence of tuberculosis (TB) throughout the world and outbreaks of multi-drug resistant (MDR) TB during the last decade demonstrate the necessity for an early and accurate diagnosis of this infectious disease ${ }^{16}{ }^{18}$. In most routine clinical laboratories the detection of Mycobacterium tuberculosis is still based on the microscopic examination of acid-fast stained smears and culture. However, staining for acid-fast bacilli (AFB) lacks sensitivity, varying from $50 \%$ to $60 \%$, and does not distinguish $\mathrm{M}$ tuberculosis from other mycobacteria ${ }^{1123}$. Cultures in solid media are more sensitive but can take 3 to 6 weeks until the results are available ${ }^{5}$. The BACTEC radiometric ( Becton-Dickinson Diagnostics, Towson, MD, USA) system, the MGIT (Becton Dickinson Diagnostics, Towson, MD, USA) culture system and nucleic acid probes have improved the speed of isolation and identification butstill require several days before a definitive diagnosis can be made ${ }^{119}$.

\footnotetext{
1. Núcleo de Doenças Infecciosas do Centro Biomédico da Universidade Federal do Espirito Santo, Vitória, ES, Brazil. Supported by TBRU.

Address to: Dr. Moisés Palaci. NDI/CB/UFES. Av. Marechal Campos 1468, Maruípe, 29040-091 Vitória, ES, Brazil.

e-mail: mpalaci@ndi.ufes.br

Tel: 5527 3335-7209, Fax: 5527 3335-7206

Recebido para publicação em 23/5/2003

Aceito em 26/7/2004
} 
Diagnostic techniques based on molecular biology methods are able to dramatically reduce the time of detection ( within hours) as well as increase the sensitivity for detecting $M$. tuberculosis. The sensitivity of non-commercial PCR assays has varied widely, from $55 \%$ to $100 \%$ in various studies ${ }^{3913} 17$. The use of commercial kits with specific procedures and controls, such as the Amplified M tuberculosis Direct Test ( Gen-Probe Inc., San Diego, CA, USA) and the Amplicor M tuberculosis test (Roche Diagnostics, Basel, Switzerland) , may reduce this interlaboratory variation ${ }^{6}$.

In the last years, ligase chain reaction (LCR) technology has become commercially available for the direct detection of $\mathrm{M}$ tuberculosis in clinical samples. The $\mathrm{LCX}^{\mathrm{TM}} \mathrm{M}$ tuberculosis Assay (Abbott Laboratories, North Chicago, IL, USA) is the first commercial semi-automated nucleic acid amplification test developed for use with respiratory specimens ${ }^{10}$. However, the clinical utility of this method, mainly concerning its sensitivity for smear-negative samples, in a population with high tuberculosis prevalence, such as in Brazil, has not been widely studied.

In this study, we evaluated the LCX ${ }^{\mathrm{TM}} \mathrm{M}$. tuberculosis assay in a clinical laboratory using pulmonary samples. A clinical case definition of tuberculosis consistent with case reporting criteria was used as the reference-standard for evaluating the utility of all diagnostic tests.

\section{MATERIAL AND METHODS}

Clinical specimens. A total of 297 respiratory specimens (sputum and bronchial lavage) from 193 patients being screened or under treatment for tuberculosis at the Pneumology Clinic of Hospital Universitário Cassiano Antônio Moraes (Espírito Santo, Brazil) were included in the study.

Sample processing. Respiratory specimens were liquefied and decontaminated with an equal volume of N-acetyl-cysteine$\mathrm{NaOH}$ to a final concentration of $2 \%$ and incubated for 15 min at room temperature. After decontamination, PBS was added to all the specimens for a final volume of $50 \mathrm{ml}$. The mixture was centrifuged at $3000 \mathrm{x} \mathrm{g}$ for $15 \mathrm{~min}$ at $4^{\circ} \mathrm{C}$ and the sediment was resuspended in PBS.

Microscopy. The sediment was subjected to microscopic examination for acid-fast bacilli (AFB) by standard procedures with fluorescent and/or Ziehl Neelsen stains ${ }^{12}$.

Culture. The sediment was inoculated in Lowenstein-Jensen medium, incubated at $3^{7}{ }^{\circ} \mathrm{C}$ for a maximum of 6 weeks and inspected weekly for growth, and cultivated in BACTEC 460 radiometric method (Becton-Dickinson Diagnostics) for 6 weeks with the growth index checked 3 times a week. The mycobacteria isolates were identified using standard methods ${ }^{12}$.

LCx MTB assay. The treated sample was processed according to the manufacturer's recommendations. Briefly, $500 \mu \mathrm{l}$ of each treated sample were put in a screw-cap microcentrifuge tube, centrifuged twice and resuspended in order to minimize the potential impact of inhibitors, inactivated for 20 min at $95^{\circ} \mathrm{C}$ in the LCx covered dry bath
(Abbott Laboratories) and lysed for $10 \mathrm{~min}$ in the LCx lysor (Abbott Laboratories). For the amplification reaction, 100 $\mu$ l of the supernatant were transferred to a ready-to-use tube containing $100 \mu \mathrm{l}$ of the LCR mixture. The specimens and controls were placed in the LCx thermal cycler and amplified for 37 cycles of incubation for $1 \mathrm{~s}$ at $94^{\circ} \mathrm{C}, 1 \mathrm{~s}$ at $64^{\circ} \mathrm{C}$ and $40 \mathrm{~s}$ at $69^{\circ} \mathrm{C}$. Amplified tubes were transferred unopened to the carousel of the LCx analyzer, which directly detects the amplification products by a microparticle enzyme immunoassay. Results were expressed as fluorescence rates and were compared to the calibrator rate. A sample rate/cutoff value ratio of $>1.0$ indicates an LCX MTB assay positive result.

Patients' clinical data. After specimen collection, the medical and epidemiological records of all patients were reviewed. In cases in which discrepant results for the LCX MTB assay and the culture were obtained, the responsible physicians were contacted and clinical data were evaluated. Clinical assessment included patient history, signs, symptoms, chest Xrays, laboratory results, and follow-up observations as well as results obtained from additional specimens previously taken from the patient.

Data analysis. The microbiological data of all patients were recorded using TB Notes Software (NDI-UFES \& Gaia Informática). Sensitivity, specificity, and positive and negative predictive values were calculated for LCX MTB as compared with standard culture of specimens and, later, with clinical data.

\section{RESULTS}

A total of 297 specimens from 193 patients (average of 1.5 samples per patient) being screened or under treatment for tuberculosis were examined by microscopy, culture and the LCx assay. Of these, 42 (14\%) were positive for mycobacteria either by solid culture or by BACTEC 460 TB. The LCx MTB Assay gave a positive result on 56 (18.8\%) samples, of which 38 (12.8\%) were positive also by culture and 18 (6\%) only by LCx MTB; $238(80.1 \%)$ samples were negative by all methods. All positive specimens were identified as M. tuberculosis. The sensitivity, specificity, positive predictive value (PPV) and negative predictive value (NPV) of the LCx test, in comparison with culture results, were $92.7 \%, 93 \%, 67.8 \%$ and $98.7 \%$, respectively (Table 1 ).

Table 1 - Comparison of LCx MTB and AFB results with culture results for detection of M. tuberculosis in 297 pulmonary samples.

\begin{tabular}{|c|c|c|c|c|c|c|}
\hline \multirow[b]{2}{*}{ Test result } & \multicolumn{2}{|c|}{ Culture } & \multirow{2}{*}{$\begin{array}{r}\text { Sens. } \\
\%\end{array}$} & \multirow{2}{*}{$\begin{array}{r}\text { Spec. } \\
\%\end{array}$} & \multirow{2}{*}{$\begin{array}{r}\text { PPV } \\
\%\end{array}$} & \multirow{2}{*}{$\begin{array}{r}\mathrm{NPV} \\
\%\end{array}$} \\
\hline & positive & negative & & & & \\
\hline$\overline{A F B}$ & & & 62.0 & 99.6 & 96.3 & 94.0 \\
\hline positive & 26 & 1 & & & & \\
\hline negative & 16 & 254 & & & & \\
\hline LCX-MTB & & & 92.7 & 93.0 & 67.8 & 98.7 \\
\hline positive & 38 & 18 & & & & \\
\hline negative & 3 & 238 & & & & \\
\hline
\end{tabular}

Sens. $=$ Sensitivity; Spec. $=$ Specificity; PPV = Positive Predictive Value; NPV = Negative Predictive Value 
The data in Table 2 demonstrate the correlation between LCx and smear/culture results. Of the 42 positive specimens, 26 were positive for AFB. The sensitivity of the LCx method was $100 \%$ for the smear-positive samples and $75 \%$ for the smear-negative samples.

A clinical case definition of tuberculosis was used as the reference-standard to determine the utility of all diagnostic tests (Table 3). In our study a total of $36(18.6 \%)$ patients were confirmed as new pulmonary tuberculosis cases. An average of 1.8 specimens was collected for these patients and they had similar culture and LCx results. There were 9 discrepant results between LCx and final clinical diagnosis (Table 4). Five patients with other respiratory problems at the time of examination had their specimens considered false positive because both follow up observation and culture results did not confirm the presence of active TB. Specimens from the remaining 4 patients were considered false-negative. One of them had a sputum positive culture and the other three patients had no bacteriological confirmation of TB but their clinical presentation and response to treatment, resulted in a final diagnosis of TB.

Table 2 - Performance of LCX-MIB in AFB smear-positive versus smearnegative samples

\begin{tabular}{lrrr}
\hline & \multicolumn{2}{c}{ LCX-MTB } & \\
\cline { 2 - 3 } Test result & positive & negative & Sensitivity \% \\
\hline AFB pos/culture pos & 26 & 0 & 100.0 \\
AFB neg/culture pos & 12 & 4 & 75.0 \\
\hline
\end{tabular}

Table 3 - Comparison of LCX-MIBand culture results for 193 patients with and without tuberculosis.

\begin{tabular}{|c|c|c|c|c|c|c|}
\hline \multirow[b]{2}{*}{ Test result } & \multicolumn{2}{|c|}{ Culture } & \multirow{2}{*}{$\begin{array}{r}\text { Sens. } \\
\%\end{array}$} & \multirow{2}{*}{$\begin{array}{r}\text { Spec. } \\
\%\end{array}$} & \multirow{2}{*}{$\begin{array}{r}\text { PPV } \\
\%\end{array}$} & \multirow{2}{*}{$\begin{array}{r}\text { NPV } \\
\%\end{array}$} \\
\hline & positive & negative & & & & \\
\hline \multicolumn{7}{|c|}{$\overline{\mathrm{AFB}}$} \\
\hline positive & 29 & 0 & 80.5 & 100.0 & 100.0 & 95.7 \\
\hline negative & 7 & 157 & & & & \\
\hline LCX-MTB & & & 88.9 & 96.8 & 86.5 & 97.4 \\
\hline positive & 32 & 5 & & & & \\
\hline negative & 4 & 152 & & & & \\
\hline
\end{tabular}

\section{DISCUSSION}

When the performance of a new diagnostic method is evaluated, the performance of a standard test is a critical parameter. For detection of M tuberculosis, culture using either conventional medium such as Lowenstein-Jensen or BACTEC 12B medium has been considered to be the gold standard. The sensitivity and specificity of these methods are often reported to be higher than $90 \%{ }^{11}{ }^{15}$. However, when nucleic acid amplification procedures are used, clinical diagnosis should also be taken into account, since the DNA detected by these methods can indicate the presence of non-viable bacilli15. For that reason, the calculated values in our study were based not only on the performance of the culture method butalso on clinical and historical laboratory data. Nucleic acid amplification test evaluations may also be biased as a result of inclusion of multiple specimens from individual patients ${ }^{4}$. The present study avoided these biases by collecting an average of only 1.5 specimens per patient.

Our results show that under routine clinical conditions both culture and LCX-MTB tests presented good analytical performances. When compared to culture, the sensitivity value (92.7\%) of the LCx-MTB assay was shown to be as high as those reported by other investigators for respiratory specimens with several amplification tests ${ }^{70} 2223$. The three negative results obtained by LCx amplification assay for culture-positive samples may be explained by the presence of inhibitors of enzymatic amplification. We did not search for the presence of inhibitory substances; however, these samples were retested and negative results were obtained upon repeat assay. Discrepancy between positive predictive values may be explained by the fact that several samples came from tuberculosis patients undergoing treatment. The long lasting ability to detect DNA after cultures become negative is well documented for DNA amplifications systems and makes LCX-MTB unsuitable for the monitoring of therapeutic efficacy $^{1521}$.

The ability of a test to detect $\mathrm{M}$ tuberculosis rapidly in AFB smear-negative samples from patients symptomatic for pulmonary TB is of obvious importance. From an operative standpoint, microscopic examination of stained smears is the

Table 4 - Analysis of discrepant results between LCX-MB and clinical diagnosis.

\begin{tabular}{|c|c|c|c|c|c|c|c|c|}
\hline \multirow[b]{2}{*}{$\begin{array}{c}\text { Patient } \\
\mathrm{n}^{0}\end{array}$} & \multirow[b]{2}{*}{$\mathrm{SR} / \mathrm{CVR}^{\mathrm{a}}$} & \multirow[b]{2}{*}{ LCx/result } & \multirow[b]{2}{*}{$\begin{array}{c}\text { Culture } \\
\text { result }\end{array}$} & \multicolumn{4}{|c|}{ Patient's } & \multirow[b]{2}{*}{$\begin{array}{c}\text { Final inter- } \\
\text { pretation of LCx }\end{array}$} \\
\hline & & & & $\mathrm{Age}^{\mathrm{b}}$ & $\operatorname{sex}^{c}$ & Clinical diagnosis $^{d}$ & Comments & \\
\hline 1 & 1.67 & t & - & 60 & M & & transient cough & FP \\
\hline 2 & 1.54 & t & - & 22 & M & & bronchitis & FP \\
\hline 3 & 1.68 & + & - & 67 & M & & COPD ${ }^{\mathrm{e}}$ & $\mathrm{FP}$ \\
\hline 4 & 4.21 & t & - & 36 & $\mathrm{~F}$ & & transient cough & $\mathrm{FP}$ \\
\hline 5 & 2.46 & + & - & 45 & $\mathrm{~F}$ & & bacterial pneumonia & $\mathrm{FP}$ \\
\hline 6 & 0.12 & - & t & 76 & M & active TB & & FN \\
\hline 7 & 0.05 & - & - & 64 & $\mathrm{~F}$ & active TB & & FN \\
\hline 8 & 0.05 & - & - & 40 & M & active TB & & FN \\
\hline 9 & 0.04 & . & - & 28 & M & active $\mathrm{TB}$ & HIV positive & $\mathrm{FN}$ \\
\hline
\end{tabular}

aSample rate/cutoff value ratio of $>1.0$. ${ }^{b}$ Age in years. ${ }^{\circ}$. female; M. male. dAssessment based on signs, symptoms, routine laboratory results, chest X rays, results of TB culture and follow up. ${ }^{\mathrm{C} C h r o n i c}$ obstructive pulmonary disease. ${ }^{\mathrm{I} F P}$ False positive; FN False negative. 
most rapid way to detect mycobacteria in respiratory tract specimens. However, it is not a very sensitive test, as 40 to $50 \%$ of patients with pulmonary tuberculosis have smear negative specimens ${ }^{51123}$. The delay in initiating drug therapy may result in progression of the disease, as well as transmission of Mycobacterium tuberculosis to others. In these cases, the rapid detection of $\mathrm{M}$. tuberculosis by a direct amplification test could lead to earlier initiation of antituberculous treatment. In our study the high sensitivity of the LCX-MTB was especially relevant for the 16 AFB-negative samples, 12 (75\%) of which were identified by LCx MTB. Several studies have demonstrated that PCR methods are significantly less sensitive (45-70\%) on AFB-negative samples, and it has been an obstacle for the use of PCR on smearnegative samples ${ }^{2} 1421$.

A clinical case definition of tuberculosis was used as the reference-standard to determine the utility of all diagnostic tests in our study. Thus, when compared to final clinical diagnosis, the sensitivity was higher for the LCR-based amplification method (88.9\%) than for the culture methods $(80.5 \%)$; however, they were lower than the sensitivities reported by Fadda et al, which were $96.8 \%$ and $92.7 \%$, respectively ${ }^{8}$. This difference could be explained by the heterogeneous group of patients selected in our study, which included patients with HIV infection and / or AIDS and patients with non-cavitary tuberculosis.

Studies have varied in their management of discrepant results $^{10} 22$ 23. Our comprehensive study, encompassing 193 patients, demonstrates only 9 discrepant results between LCX and final clinical diagnosis. Five patients had their specimens considered false positive, although the follow-up was too short to exclude eventual active tuberculosis. The false-negative results for 4 patients may be explained by (i) the presence of possible amplification inhibitors in the sample; (ii) a non-uniform distribution of microorganisms in the test suspension; or (iii) a low concentration of microorganisms in the sample.

In summary, our study demonstrated that LCR-MTB is a sensitive and specific method for the detection of M. tuberculosis in respiratory specimens. The assay protocols were easy to perform and were suitable for the work flow of a routine microbiology laboratory. LCR-MTB provides the clinician and infection control program with valuable, rapid and clinically relevant information for the diagnosis of pulmonary tuberculosis. However, the LCR assay should not be considered a substitute but rather a complement to traditional microbiology techniques, with the aim of increasing the sensitivity and speed of diagnosis of tuberculosis.

\section{ACKNOWLEDGEMENTS}

We thank Abbott Laboratórios do Brasil for supplying the LCx MTB Assay kits and Neil Gupta for help in preparation of the manuscript. We also acknowledge the Tuberculosis Research Unit - TBRU for technical support.

\section{REFERENCES}

1. Anargyros P, Astill DSJ, Lim ISL. Comparison of improved BACTEC and Lowenstein-Jensen media for culture of mycobacteria from clinical specimens. Journal of Clinical Microbiology 28: 1288-1291, 1990.

2. Bergmann JS, Woods GL. Clinical evaluation of the Roche Amplicor PCR Mycobacterium tuberculosis test for detection of Mycobacterium tuberculosis in respiratory specimens. Journal of Clinical Microbiology 34: 1083-1085, 1996

3. Brisson-Noel A, Aznar C, Chureau C, Nguyen S, Pierre C, Bartoli M, Bonete R, Pialoux G, Gicquel B, Garrigue G. Diagnosis of tuberculosis by DNA amplification on clinical practice evaluation. The Lancet 338: 364-366, 1991.

4. Charache P. Comparison of the amplified Mycobacterium tuberculosis (MTD) direct test, Amplicor MTB PCR, and IS 6110-PCR for detection of MTB in respiratory specimens. Clinical Infectious Diseases (Editorial response) 23: 1107-1108, 1996.

5. Chin DP, Yajko DM, Hadley WK, Sanders CA, Nassos PS, Madej JJ, Hopewell PC. Clinical utility of a commercial test based on the polymerase chain reaction for detecting Mycobacterium tuberculosis in respiratory specimens. American Journal of Respiratory Critical Care Medicine 151: 1872-1877, 1995.

6. D'Amato RF, Wallman AA, Hochstein LH, Colaninno PM, Scardamaglia M, Ardila E, Ghouri M, Kim K, Patel RC, Miller. A rapid diagnosis of pulmonary tuberculosis by using Roche Amplicor Mycobacterium tuberculosis PCR test. Journal of Clinical Microbiology 33: 1832-1834, 1995.

7. Denis O, Devaster JM, Vandenberg O, Vanachter H, Lafontaine T, Lin C, Butzler JP. Evaluation of ligase chain reaction for direct detection of Mycobacterium tuberculosis in respiratory specimens. Zentralbl Bakteriol 288: 59-65, 1998.

8. Fadda G, Ardito F, Sanguinetti M, Posterado B, Ortona L, Chezzi C, Polonelli L, Dettori G, Conti S, Fanti F, Galli C. Evaluation of the Abbott LCX Mycobacterium tuberculosis assay in comparison with culture methods in selected Italian patients. New Microbiology 21: 97-103, 1998.

9. Forbes BA, Hicks KES. Direct detection of Mycobacterium tuberculosis in respiratory specimens in a clinical laboratory by polymerase chain reaction. Journal of Clinical Microbiology 31: 1688-1694, 1993.

10. Gamboa F, Dominguez J, Padilla E, Manterola JM, Gazapo E, Lonca J, Matas L, Hernandez A, Cardona PJ, Ausina V. Rapid diagnosis of extrapulmonary tuberculosis by ligase chain reaction amplification. Journal of Clinical Microbiology 36: 1324-1329, 1998.

11. Gordin F, Slutkin G. The validity of acid-fast smears in the diagnosis of pulmonary tuberculosis. Archives of Pathology and Laboratory Medicine 114: 1025-1027, 1990.

12. Kent PT, Kubica GP. Public health mycobacteriology. A guide for the level III laboratory. Atlanta, Ga: Centers for Disease Control, U.S. Department of Health and Human Services, 1985.

13. Kirschner P, Rosenau J, Springer B, Teschner K, Feldmann K, Boettger EC. Diagnosis of mycobacterial infections by nucleic acid amplification: 18-month prospective study. Journal of Clinical Microbiology 34: 304-312, 1996.

14. Moore DF, Curry JI. Detection and identification of Mycobacterium tuberculosis directly from sputum sediments by Amplicor PCR. Journal of Clinical Microbiology 33: 2686-2691, 1995

15. Noordhoek GT, Kaan JA, Mulder S, Wilke H, Kolk AHJ. Application of the polymerase chain reaction in a routine microbiology laboratory for detection of Mycobacterium tuberculosis in clinical samples. Journal of Clinical Pathology 48: 810-814, 1995.

16. Pablos-Mendez A, Raviglione MC, Laszlo A, Binkin N, Rieder HL, Bustreo F, Cohn DL, Lambregts-van Weezenbeek CS, Kim SJ, Chaulet P, Nunn P. Global surveillance for antituberculosis-drug resistance, 1994-1997. World Health Organization-International, Union against tuberculosis and Lung Disease Working Group on Anti-Tuberculosis Drug Resistance Surveillance. The New England Journal of Medicine 338: 1641-1649, 1998.

17. Palaci M, Ueki SYM, Sato DN, Telles MAS, Curcio M, Silva EAM. Evaluation of mycobacteria indicator tube for recovery and drug susceptibility testing 
of Mycobacterium tuberculosis isolates from respiratory specimens. Journal of Clinical Microbiology 34: 762-764, 1996.

18. Pfyffer GE, Kissling P, Jahn EM, Welscher HM, Salfinger M, Weber R. Diagnostic performance of amplified Mycobacterium tuberculosis direct test with cerebrospinal fluid, other non-respiratory, and respiratory specimens. Journal of Clinical Microbiology 34: 834-841, 1996.

19. Piersimoni CA, Callegaro A, Nista D, Bornigia S, De Conti F, Santini G, De Sio G. Comparative evaluation of two commercial amplification assays for direct detection of Mycobacterium tuberculosis complex in respiratory specimens. Journal of Clinical Microbiology 35: 193-196, 1997.

20. Ruiz-Serrano MJ, Albadalejo J, Martinez-Sanchez L, Bouza E. LCx: a diagnostic alternative for the early detection of Mycobacterium tuberculosis complex. Diagnostic Microbiology and Infectious Disease 32: 259-264, 1998.
21. Schluger NW, Rom WN. Current approaches to the diagnosis of active pulmonary tuberculosis. American Journal of Respiratory and Critical Care Medicine 149: 264-267, 1994.

22. Tortoli E, Lavinia F, Simonetti MT. Evaluation of a commercial amplification ligase chain reaction kit (Abbott LCx) for direct detection of Mycobacterium tuberculosis in pulmonary and extrapulmonary specimens. Journal of Clinical Microbiology 35: 2424-2426, 1997.

23. Tortoli E, Tronci M, Tosi CP, Galli C, Lavinia F, Natili S, Goglio A. Multicenter evaluation of two commercial amplification kits (Amplicor, Roche and LCX, Abbott) for direct detection of Mycobacterium tuberculosis in pulmonary and extrapulmonary specimens. Diagnostic Microbiology and Infectious Disease 33: 173-179, 1999. 